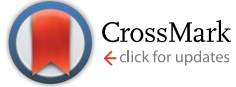

Cite this: J. Mater. Chem. B, 2015, 3, 1760

Received 17th December 2014 Accepted 9th January 2015

DOI: $10.1039 / c 4 t b 02079 k$

www.rsc.org/MaterialsB

\section{Integrating silver compounds and nanoparticles into ceria nanocontainers for antimicrobial applications $\dagger$}

\author{
J. Gagnon, ${ }^{\star a}$ M. J. D. Clift, ${ }^{\text {b }}$ D. Vanhecke, ${ }^{\text {b D. A. Kuhn, }}{ }^{\text {b }}$ P. Weber, ${ }^{a}$ A. Petri-Fink, ${ }^{b}$ \\ B. Rothen-Rutishauser ${ }^{b}$ and K. M. Fromm*a
}

Silver compounds and nanoparticles (NPs) are gaining increasing interest in medical applications, specifically in the treatment and prevention of biomaterial-related infections. However, the silver release from these materials, resulting in a limited antimicrobial activity, is often difficult to control. In this paper, ceria nanocontainers were synthesized by a template-assisted method and were then used to encapsulate silver nitrate $\left(\mathrm{AgNO}_{3} / \mathrm{CeO}_{2}\right.$ nanocontainers). Over the first 30 days, a significant level of silver was released, as determined using inductively coupled plasma optical emission spectroscopy (ICP$\mathrm{OES})$. A novel type of ceria container containing silver $\mathrm{NPs}\left(\mathrm{AgNP} / \mathrm{CeO}_{2}\right.$ containers) was also developed using two different template removal methods. The presence of AgNPs was confirmed both on the surface and in the interior of the ceria containers by X-ray diffraction (XRD), transmission electron microscopy (TEM) and scanning electron microscopy (SEM). Upon removal of the template by calcination, the silver was released over a period exceeding three months ( $>90$ days). However, when the template was removed by dissolution, the silver release was shortened to $\leq 14$ days. The antimicrobial activity of the silver-containing $\mathrm{CeO}_{2}$ containers was observed and the minimum bactericidal concentration (MBC) was determined using the broth dilution method. Investigation on human cells, using a model epithelial barrier cell type (A549 cells), highlighted that all three samples induced a heightened cytotoxicity leading to cell death when exposed to all containers in their raw form. This was attributed to the surface roughness of the $\mathrm{CeO}_{2}$ nanocontainers and the kinetics of the silver release from the $\mathrm{AgNO}_{3} / \mathrm{CeO}_{2}$ and $\mathrm{AgNP} / \mathrm{CeO}_{2}$ nanocontainers. In conclusion, despite the need for further emphasis on their biocompatibility, the concept of the $\mathrm{AgNP} / \mathrm{CeO}_{2}$ nanocontainers offers a potentially alternative long-term antibactericidal strategy for implant materials.

\section{Introduction}

Implant-associated bacterial infections remain a significant issue. In the U.S.A., $4.3 \%$ of implants inserted into humans become infected. ${ }^{\mathbf{1 , 2}}$ Bacteria that adhere at the site of implantation can create a biofilm, ${ }^{3}$ competing with the host tissues for integration with the implant as well as proper host cell integration, both essential aspects for the biocompatibility of any implant. Once bacteria adhere to a biomaterial surface, they are very difficult to be removed by the host immune system or displaced by the host cells. ${ }^{4}$ Thus preventing bacterial

${ }^{a}$ Department of Chemistry and Fribourg Center for Nanomaterials, University of Fribourg, Chemin du Musée 9, 1700 Fribourg, Switzerland. E-mail: Katharina. Fromm@unifr.ch; Jacinthe.Gagnon@iaf.inrs.ca; Fax: +41 26 3009738; Tel: +41 26 3008732

${ }^{b}$ Adolphe Merkle Institute and Fribourg Center for Nanomaterials, University of Fribourg, Route de l'Ancienne Papeterie, P.O. Box 209, 1723 Marly, Switzerland

$\dagger$ Electronic supplementary information (ESI) available. See DOI: 10.1039/c4tb02079k contamination during and after surgery improves the host tissue integration of the implant. It has been demonstrated that the decisive period for preventing bacterial invasion relates to only 6 hours after surgery. ${ }^{5}$ Infections can lead to additional pain for the patient as well as malfunction of the implant, which in turn leads to a need for its replacement, or in extreme cases to amputation or even death of the patient. From an economical point of view, bacterial infections also create considerable additional medical costs which could be avoided if bacterial invasion is prevented. ${ }^{2}$ Moreover, implants are being increasingly used and at the same time bacteria are becoming more resistant to conventional antibiotics. ${ }^{6}$ Therefore, there is an essential need for new developments in preventing and curing implant-related bacterial infections.

In this context, silver compounds and nanoparticles (NPs) are gaining more interest from the scientific community as a possible replacement for commonly used antibiotics, such as penicillin. Silver-containing materials may be used to coat implants in order to prevent bacterial biofilm formation. However, these compounds may be too soluble and even promote adverse effects 
towards the host if the silver release is not controlled. ${ }^{7}$ Ideally, the release of silver ions should be able to kill bacteria without affecting biocompatibility. The release of silver ions, however, largely depends on the environment (i.e. $\mathrm{pH}$, ionic strength, organic matter) and is therefore difficult to control in the human body. As we have shown in previous reports, it is possible to design the light stability and solubility of silver coordination polymers as efficient antimicrobial coatings for implant materials. ${ }^{89}$ However, with these compounds the silver release occurs permanently, irrespective of the presence of bacteria.

Another strategy to control the release of silver is the integration of silver NPs (AgNPs) into a biocompatible coating, ${ }^{\mathbf{1 0}}$ or directly into the biomaterials, such as in bone cements. ${ }^{11}$ In addition to such outlooks, encapsulation of AgNPs can be advantageous in order to control and prolong the release of different compounds, ${ }^{\mathbf{1 2 , 1 3}}$ in turn increasing the stability and biocompatibility of silver drugs. Encapsulation is also of great interest for many medical applications, such as targeted drug delivery. ${ }^{14}$ For example, it has been shown that encapsulated drugs are thermally more resistant. ${ }^{\mathbf{1 3 , 1 5}}$

Ceria $\left(\mathrm{CeO}_{2}\right)$ is an excellent material for encapsulating drugs since it is highly stable for long time periods in aqueous solutions and elicits limited adverse biological effects. ${ }^{16,17}$ It has been demonstrated that $\mathrm{CeO}_{2}$-NPs can elicit certain antioxidant properties that protect cells against the onset of oxidative stress. ${ }^{16,18}$ The aim of the present study, therefore, was to determine if it were possible to specifically encapsulate silver compounds and/or NPs within ceria-based container systems in order to slow down the silver release and thus making silver coatings increase their active antimicrobial period. Two approaches were envisaged to fill nanocontainers with silver compounds. A first method was to make hollow spheres and then fill them with the desired compound by soaking, resulting in the $\mathrm{AgNO}_{3} / \mathrm{CeO}_{2}$ nanocontainers. Secondly, it is also possible to include the AgNPs during the synthesis of the nanocontainers. Both methods are hereby described with the resultant material's characterization. The silver release was measured over a period of 3 months. The antimicrobial activity and the cytotoxicity of the novel $\mathrm{AgNO}_{3} / \mathrm{CeO}_{2}$ and $\mathrm{AgNP} / \mathrm{CeO}_{2}$ containers were evaluated in prokaryotic and eukaryotic systems respectively.

\section{Experimental}

\subsection{Materials and reagents}

All materials were obtained from Sigma-Aldrich, Switzerland. Cerium(III) acetylacetonate (Ce(acac) $\left.)_{3}\right)$, polyvinylpyrrolidone (PVP, average molecular weight: 40000 ), potassium persulfate (KPS), silver(I) oxide $\left(\mathrm{Ag}_{2} \mathrm{O}\right)$, silver(I) nitrate $\left(\mathrm{AgNO}_{3}\right)$, sodium dodecyl sulfate (SDS), urea and ethanol were of analytical grade and used without further purification. Styrene and water were doubly distilled prior to use. Lysogeny broth (LB) medium and agar plates were obtained "ready-for-use".

\subsection{Polystyrene nanosphere (PS NS) synthesis}

Anionic PS NSs were synthesized via emulsion polymerization. ${ }^{\mathbf{1 9}}$ The reaction mixture was prepared by mixing styrene $(3.70 \mathrm{~g}$,
$35.5 \mathrm{mmol}$ ), KPS (0.30 g, $1.1 \mathrm{mmol}$ ), and SDS (0.09 g, $0.3 \mathrm{mmol})$ in water $(250 \mathrm{~mL})$. The solution was stirred at $80{ }^{\circ} \mathrm{C}$ under argon for 42 hours. The PS NSs were then washed three times by centrifugation (30 min at $10000 \mathrm{rpm}$ ). The supernatant was subsequently discarded and the pellets re-suspended in water.

\section{3 $\mathrm{CeO}_{2}$ container synthesis}

The $\mathrm{CeO}_{2}$ containers were formed via a sol-gel method: $:^{13}$ PS NSs (0.3 g), Ce(acac) $)_{3}(0.7 \mathrm{~g}, 1.6 \mathrm{mmol})$, PVP (0.3 g, $\left.0.0075 \mathrm{mmol}\right)$, urea $(0.3 \mathrm{~g}, 5.0 \mathrm{mmol})$ and water $(40 \mathrm{~mL})$ were mixed for 5 minutes. The reaction was then allowed to proceed at $100{ }^{\circ} \mathrm{C}$ for 4 to 5 days without any agitation. Urea was used to prevent aggregation but had no effect on the reaction. ${ }^{13}$ The suspension was centrifuged for $30 \mathrm{~min}$ at $15000 \mathrm{rpm}$. The supernatant was discarded and the pellets were re-suspended in water using sonication. This washing step was repeated 3 times and the PS NSs coated with $\mathrm{CeO}_{2}$ were dried in an oven at $40{ }^{\circ} \mathrm{C}$ for 1 day. Hollow $\mathrm{CeO}_{2}$ containers were obtained by removing the PS core by calcination in air in an oven at $600{ }^{\circ} \mathrm{C}$ for 4 hours.

\subsection{Encapsulation of $\mathrm{AgNO}_{3}$ in $\mathrm{CeO}_{2}$ containers}

$\mathrm{AgNO}_{3}$ was encapsulated into $\mathrm{CeO}_{2}$ containers using a method adapted from Kartsonakis et al. ${ }^{13}$ Briefly, $\mathrm{CeO}_{2}$ containers were placed in a closed vial and submitted to a vacuum. They were then rapidly immersed in a saturated solution of $\mathrm{AgNO}_{3}$ in ethanol and the mixture was stirred at room temperature for 2 hours in the closed vial. The mixture was centrifuged and the supernatant was discarded. The $\mathrm{AgNO}_{3} / \mathrm{CeO}_{2}$ containers were washed three times with fresh ethanol and collected by centrifugation (10 min at $10000 \mathrm{rpm}$ ). They were then dried overnight at room temperature.

\subsection{Silver nanoparticle (AgNP) synthesis}

The method used to synthesize AgNPs was adapted from Evanoff and Chumanov. ${ }^{20}$ A $250 \mathrm{~mL}$ flask was filled with PS NSs $(0.140 \mathrm{~g})$ and silver(I) oxide $(0.045 \mathrm{~g}, 0.2 \mathrm{mmol})$ in water $(60 \mathrm{~mL})$. The flask was then placed into an autoclave. The autoclave was filled with 10 bar $\mathrm{H}_{2}$ and the reaction was allowed to proceed at $70{ }^{\circ} \mathrm{C}$ for 4 hours with constant stirring. After cooling, the mixture was centrifuged (15 min at $15000 \mathrm{rpm}$ ). The supernatant was discarded and the pellets were re-suspended in water (5 mL).

\subsection{Encapsulation of AgNPs in PS NSs}

The method used to encapsulate the AgNPs into the PS beads was adapted from Kumbhar and Chumanov. ${ }^{21}$ After the AgNP synthesis, the mixture $(2 \mathrm{~mL})$ was added to acetone $(5 \mathrm{~mL})$ and sonicated for 4 hours at room temperature. The resulting mixture was centrifuged (15 $\mathrm{min}$ at $15000 \mathrm{rpm}$ ) and the pellets were resuspended in water $(5 \mathrm{~mL})$.

\section{7 $\mathrm{AgNP} / \mathrm{CeO}_{2}$ container synthesis}

The PS NSs encapsulating AgNPs were coated with $\mathrm{CeO}_{2}$, similar to the synthesis of the $\mathrm{CeO}_{2}$ nanocontainers: the obtained AgNP/PS spheres (0.12 g), Ce(acac) ${ }_{3}$ (0.50 g, $\left.1.1 \mathrm{mmol}\right)$, PVP 
$(0.300 \mathrm{~g}, 0.0075 \mathrm{mmol})$, urea $(0.20 \mathrm{~g}, 3.3 \mathrm{mmol})$ and water (30 $\mathrm{mL}$ ) were mixed for $5 \mathrm{~min}$. Then the reaction was allowed to proceed at $100{ }^{\circ} \mathrm{C}$ for 4 to 5 days without any agitation. The suspension was centrifuged for $30 \mathrm{~min}$ at $15000 \mathrm{rpm}$. The supernatant was discarded and the pellets were re-suspended in water using sonication. The washing step was repeated three times and the AgNP/PS NSs coated with $\mathrm{CeO}_{2}$ were dried in an oven at $40{ }^{\circ} \mathrm{C}$ for at least one day. Hollow $\mathrm{AgNP} / \mathrm{CeO}_{2}$ containers were obtained by calcination in air in an oven at $600{ }^{\circ} \mathrm{C}$ for 4 hours, or by many successive dissolution treatments in boiling xylene containing triethylamine for 12 hours. $^{12}$ Formed containers were then allowed to dry in an oven at $40{ }^{\circ} \mathrm{C}$.

\subsection{Characterization}

The synthesized particles were visualized by transmission electron microscopy (TEM) using a FEI/Philips CM-100 Biotwin microscope. The TEM grids used were 300 square mesh copper TEM grids covered by a carbon film, provided by Electron Microscopy Sciences, USA. The particles were also visualized by scanning electron microscopy (SEM) using a FEI XL 30 Sirion FEG. SEM samples were prepared by spreading them on a carbon tape glued on a SEM holder. All images were obtained without sputter coating pretreatment. Images were obtained at different voltages using the Everhart-Thornley detector (EDT) or solid state detector (SSD) either in contrast or back-scattering mode. X-ray diffraction (XRD) patterns were measured using a STOE transmission X-ray powder diffraction system. Fourier transform infrared (FTIR) spectra were obtained with a Bruker Tensor 27 FTIR and a MKII Golden Gate Single Attenuated Total Reflection System. Thermogravimetric analysis (TGA) was performed in a Mettler Toledo SDTA/TGA 851e ids. The silver concentration was determined by inductively coupled plasma optical emission spectroscopy (ICP-OES) using a Perkin Elmer Optima 7000DV ICP-OES. To assess the morphology of the A549 cells following exposure to the different $\mathrm{CeO}_{2}$ nanocontainers, an inverted Zeiss laser scanning microscope (LSM) 710 Meta, Switzerland, was used.

\subsection{Silver release}

In order to determine the silver release from $\mathrm{AgNO}_{3} / \mathrm{CeO}_{2}$ nanocontainers and $\mathrm{AgNP} / \mathrm{CeO}_{2}$ containers, 4 duplicates (75 $\mathrm{mg}$ ) of each sample were prepared. Each duplicate was placed in a well, covered with distilled water $(1.2 \mathrm{~mL})$ and left at room temperature in the dark. At certain time intervals over a 3 month period, a fraction of the supernatant $(0.500 \mathrm{~mL})$ was collected and added to $1 \%$ nitric acid solution $(5 \mathrm{~mL})$ and was then ready for silver concentration determination. Freshly distilled water $(0.500 \mathrm{~mL})$ was placed back into the well. The silver concentration in each aliquot was determined by ICPOES.

\subsection{Antibacterial tests}

The Escherichia coli (E. coli) K-12 bacterial strain was used for both zone of growth inhibition determination and minimum bactericidal concentration (MBC) determination.
Zone of growth inhibition determination. The zones of inhibition for $\mathrm{CeO}_{2}, \mathrm{AgNO}_{3} / \mathrm{CeO}_{2}$ and $\mathrm{AgNP} / \mathrm{CeO}_{2}$ container powders were determined by the agar diffusion method. ${ }^{22,23}$ Initially, pellets of $90 \mathrm{mg}$ of sample were made using a press under 3 tons for 1 minute. A single-cell colony was dipped in 1 $\mathrm{mL} \mathrm{LB}$ broth and was incubated for 2 hours at $37^{\circ} \mathrm{C}$. A total of $0.100 \mathrm{~mL}$ of the resulting bacterial broth was spread on an LB agar plate until dry. The container pellet of interest was then carefully placed on the plate. The plate was then incubated overnight at $37^{\circ} \mathrm{C}$. The zone of growth inhibition, i.e. the zone on which no bacteria grew, was then measured according to the distance between the sample and the start of bacterial growth.

MBC determination. The broth macrodilution method was chosen for the determination of the MBC. The following method was adapted from the protocol described by Wiegand et al. ${ }^{24}$ Briefly, saturated $E$. coli in a LB medium was obtained by inoculating a single-cell colony in $1 \mathrm{~mL}$ of $\mathrm{LB}$ medium and incubating it at $37{ }^{\circ} \mathrm{C}$ overnight. The next day, $50 \mu \mathrm{L}$ of the saturation solution was inoculated in a fresh LB medium $(5 \mathrm{~mL})$ and incubated at $37^{\circ} \mathrm{C}$ for 2 hours. During this time, solutions containing different concentrations ranging between 6 and 240 $\mathrm{mg} \mathrm{mL}{ }^{-1}$ of $\mathrm{CeO}_{2}$ nanocontainers, $\mathrm{AgNO}_{3} / \mathrm{CeO}_{2}$ nanocontainers and $\mathrm{AgNP} / \mathrm{CeO}_{2}$ containers were prepared in the LB medium. After the two-hour incubation, the bacterial suspension was adjusted to the McFarland 0.5 standard..$^{25}$ If not concentrated enough, the suspension was incubated for another hour and if too concentrated it was diluted with a fresh LB medium. This corresponded to approximately $1.5 \times 10^{8} \mathrm{cfu} \mathrm{mL}^{-1}$. This bacterial suspension was added to each of the nanocontainer suspensions in a 1:1 ratio. A sterility control, composed of a fresh LB medium, was also prepared. A total of $100 \mu \mathrm{L}$ of each new suspension was then placed on a LB agar plate and incubated overnight at $37^{\circ} \mathrm{C}$. The following day, the concentration at which total inhibition of bacterial growth occurred was recorded.

\subsection{Cell culture and exposure}

The A549 cell line, an adenocarcinomic human alveolar Type II epithelial cell culture (ATCC, USA), was cultured as previously described by Rothen-Rutishauser et al. ${ }^{26}$

The experiments were performed on BD Falcon 2-chamber culture slides. Each well had a growth surface area of $4 \mathrm{~cm}^{2}$. The day before exposure, nanocontainer samples of $58 \mathrm{mg}$ and 174 $\mathrm{mg}$ were suspended in a cell culture medium $(2 \mathrm{~mL})$ and added to a well of the chamber slide. The samples were then incubated overnight at $37{ }^{\circ} \mathrm{C}$ and $5 \% \mathrm{CO}_{2}$. The following day, the supernatant was removed and replaced with $2 \mathrm{~mL}$ of culture medium containing $0.5 \times 10^{6}$ cells per $\mathrm{mL}$. The samples were then incubated at $37{ }^{\circ} \mathrm{C}$ and $5 \% \mathrm{CO}_{2}$ for 4 and 7 days. After each exposure period, the supernatant was removed and was used to determine the level of epithelial cell cytotoxicity.

\subsection{Epithelial cell cytotoxicity}

Cytotoxicity was determined by assessment of cell membrane damage (permeability) via measuring the release of the cytosolic enzyme lactate dehydrogenase (LDH) in the cell supernatant. 
$\mathrm{LDH}$ is the enzyme responsible for the conversion of pyruvate into lactate in the glycolysis pathway and is present in the cytosol of eukaryotic cells. Upon disruption to the cell membrane $\mathrm{LDH}$ can be released from the cytosol and subsequently measured in the cell culture medium as a measure of cell damage (i.e. cytotoxicity). Following exposure to 58 and 174 mg per well for 4 and 7 days at $37{ }^{\circ} \mathrm{C}, 5 \% \mathrm{CO}_{2}$, $\mathrm{LDH}$ levels were determined using a diagnostic kit (Roche Applied Sciences, Switzerland). As a positive control, $0.2 \%$ TritonX-100 in PBS was used. A negative control of the cell culture medium only was also performed along with each sample series. All analysis was repeated in triplicate $(n=3)$.

\subsection{Epithelial cell morphology}

Initially, following the exposure period, cells were fixed and labelled as previously described by Lehmann et al. ${ }^{27}$ Briefly, samples were labelled with a $250 \mu \mathrm{L}$ mix of a $1: 50$ dilution of phalloidin-rhodamine (label for cell cytoskeleton) and $1: 100$ dilution of 4',6-diamidino-2-phenylindole (DAPI stain for cell nuclei). Coverslips were then inverted and mounted onto microscope slides using Glycergel (Dako, Carpinteria, USA) and imaged by LSM.

\subsection{Statistical and data analysis}

The results from the silver release experiments and antibacterial tests are presented as the mean \pm standard error of the mean. All cytotoxicity data are also presented as the mean \pm standard error of the mean. This latter dataset was found to be normally distributed (data not shown) and so a parametric twoway ANOVA was conducted with subsequent Tukey's post-hoc test (SPSS, IBM, USA). Datasets were considered significant if $p<$ 0.05 . Cytotoxicity analysis was performed in triplicate $(n=3)$, while silver release experiments were performed in 4 duplicates $(n=4)$.

\section{Results and discussion}

\subsection{Encapsulation of $\mathrm{AgNO}_{3}$ into ceria nanocontainers}

In a first attempt, $\mathrm{CeO}_{2}$ nanocontainers were prepared by a procedure similar to that described by Kartsonakis et al.,${ }^{19} \mathrm{using}$ PS NSs as a template. The slightly adapted synthesis route yields white PS NSs of $220 \pm 15 \mathrm{~nm}$ diameter. After coating with $\mathrm{CeO}_{2}$ and removing the core by calcination at $600{ }^{\circ} \mathrm{C}$, pale yellow nanocontainers with diameters between 175 and $200 \mathrm{~nm}$ and shell wall thicknesses of 12 to $20 \mathrm{~nm}$ were obtained. To introduce $\mathrm{AgNO}_{3}$ into the containers, the nanocontainers were exposed to a vacuum in order to remove the air within the sample and were then immersed in a saturated solution of $\mathrm{AgNO}_{3}$ in ethanol for 2 hours. In order to test if $\mathrm{AgNO}_{3}$ was integrated into the containers, thermogravimetric analysis (TGA) was performed on the obtained grey $\mathrm{CeO}_{2}$ nanocontainers previously dried in an oven at $60{ }^{\circ} \mathrm{C}$ under a vacuum and on free $\mathrm{AgNO}_{3}$ (Fig. 1). $\mathrm{CeO}_{2}$ containers alone (Fig. 1A) did not have any significant weight loss. Free $\mathrm{AgNO}_{3}$ (Fig. 1B) underwent thermal decomposition at $370-430{ }^{\circ} \mathrm{C}$. The $\mathrm{AgNO}_{3}$ containing $\mathrm{CeO}_{2}$ nanocontainers (Fig. 1C) showed a weight loss not only in the same temperature range, which corresponds to free $\mathrm{AgNO}_{3}$, but also at $30-220{ }^{\circ} \mathrm{C}, 220-290{ }^{\circ} \mathrm{C}$ and $780-900{ }^{\circ} \mathrm{C}$. This first weight loss corresponds to desorption of physically adsorbed water. The weight loss at $220-290{ }^{\circ} \mathrm{C}$ corresponds to the encapsulated ethanol that was used as a solvent during the encapsulation. Such a difference in thermal decomposition of ethanol is due to the protection of the encapsulated ethanol in the $\mathrm{CeO}_{2}$ shell. The weight loss at $780-900{ }^{\circ} \mathrm{C}$ still remains uncertain, although there is convincing evidence that this could be due to the formation of AgNPs in the $\mathrm{CeO}_{2}$ shell from the reduction of $\mathrm{AgNO}_{3}$.

$\mathrm{CeO}_{2}$ can be photosensitized. ${ }^{28}$ It may thus be inferred that simple day light is responsible for the blackening of the $\mathrm{CeO}_{2}$ nanocontainers, reducing part of the $\mathrm{Ag}^{+}$from $\mathrm{AgNO}_{3}$ to $\mathrm{Ag}(0)$. SEM images of these nanocontainers confirmed the presence of a few AgNPs (Fig. S1†). Silver release from these $\mathrm{AgNO}_{3} / \mathrm{CeO}_{2}$ nanocontainers showed an enhanced release during the first 5 days after immersion in water. Thereafter, the silver release considerably slowed and reached a threshold after approximately 30 days (Fig. 2). This release pattern is comparable to the silver release from many other materials. ${ }^{29,30}$

\subsection{Synthesis of $\mathrm{AgNP} / \mathrm{CeO}_{2}$ containers}

In order to further control the release of silver ions from the containers, the potential to encapsulate AgNPs within a $\mathrm{CeO}_{2}$ nanocontainer shell was investigated. Depending on the pore size of the ceria container wall, it was expected that this process would be increasingly complex and so it was subsequently assumed that this encapsulation method would not be appropriate in this specific case. Thus, to include AgNPs in the nanocontainers during their synthesis an alternative method was used. Based on the work by Evanoff and Chumanov ${ }^{20}$ and Kumbhar and Chumanov, ${ }^{21}$ AgNPs of approximately $40 \mathrm{~nm}$ were synthesized via reduction with $\mathrm{H}_{2}$ in the presence of PS NSs before being embedded within them. The so-synthesized AgNPs easily adhered to the PS NSs (Fig. 3). After sonication in an acetone/water solution, they were all encapsulated inside the beads, as confirmed by TEM images (Fig. 4). Following encapsulation, the formed hybrid AgNP/PS spheres became

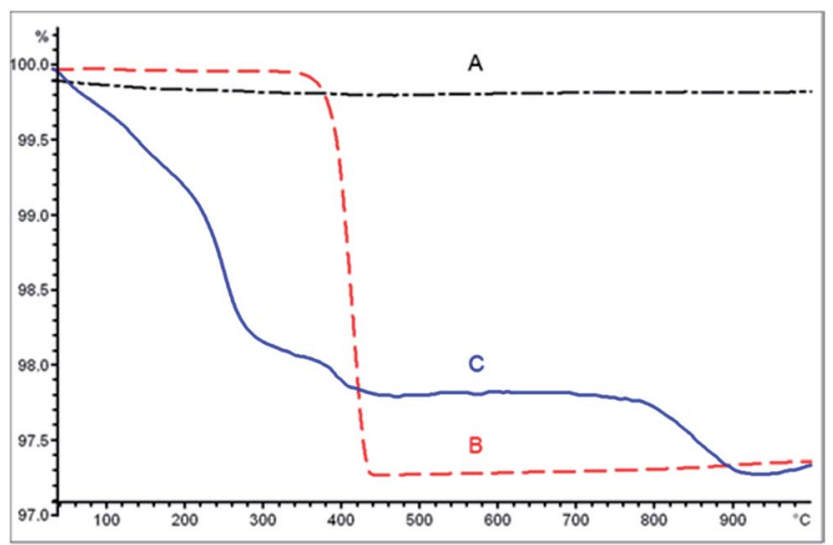

Fig. 1 TGA of untreated $\mathrm{CeO}_{2}$ nanocontainers (A), free $\mathrm{AgNO}_{3}(\mathrm{~B})$ and $\mathrm{AgNO}_{3} / \mathrm{CeO}_{2}$ nanocontainers (C). 


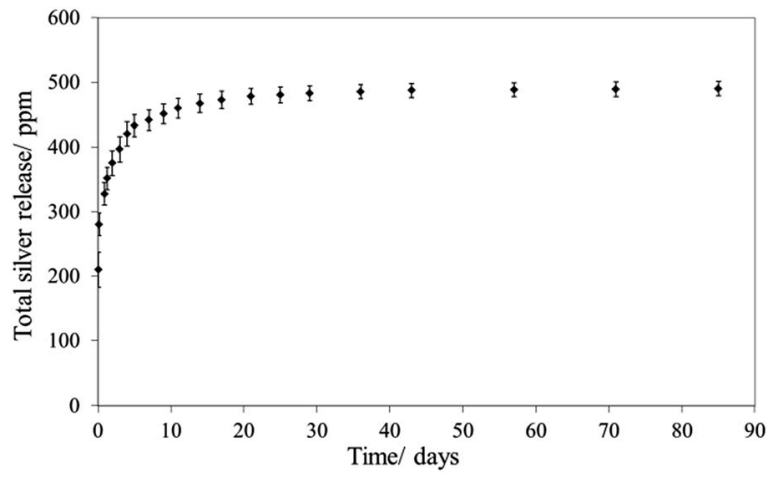

Fig. 2 Silver release as a function of immersion time in water for $\mathrm{CeO}_{2}$ containers containing $\mathrm{AgNO}_{3}$. Data are the $\%$ mean \pm standard error of the mean compared to the positive control $(n=4)$.

polydispersed, and their diameters varied between $220 \mathrm{~nm}$ and $>1 \mu \mathrm{m}$, as determined by TEM. This diverse size range was attributed to the incorporation of the AgNPs and the coalescence between the PS NSs.

The hybrid AgNP/PS spheres were then coated with $\mathrm{CeO}_{2}$ as described above. The X-ray diffraction (XRD) pattern (Fig. 5) showed that the particles were composed of ceria (JCPS no. 340394) and elemental silver (JCPS no. 04-0783), while polystyrene was not detected as a crystalline component. As determined by TEM and SEM, the diameter of the containers varied from 150 $\mathrm{nm}$ to $12 \mu \mathrm{m}$ and the ceria shell thickness varied from $15 \mathrm{~nm}$ to $20 \mathrm{~nm}$. Surprisingly, some AgNPs could also be seen on the outside surface of the $\mathrm{CeO}_{2}$ shells (Fig. 6B). In order to construct hollow spheres, the PS core was removed either by heating the spheres to $600{ }^{\circ} \mathrm{C}$ or via a dissolution process with xylene. After the PS removal, the AgNPs were still evidently present on the surface of the $\mathrm{CeO}_{2}$ nanocontainers (Fig. 6D and F). The difference of texture seen in these SEM images of the containers can be attributed to the treatment method used to remove the core material. When the polystyrene core was removed by calcination, the nanocontainer surface contained numerous pores and cracks, although the containers remained closed (Fig. 6C and D). Alternatively, when the PS core was removed by dissolution, the containers conserved their smooth surface (Fig. 6E and F). With both methods, the polystyrene core was removed, as shown by the loss of bands corresponding to the polystyrene on the IR spectra (Fig. S2 $\dagger$ ).

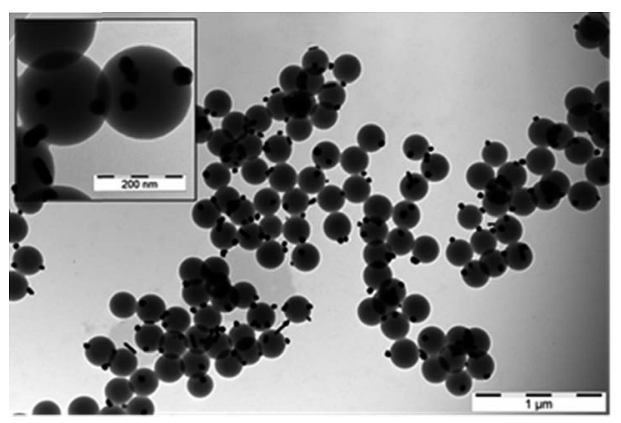

Fig. 3 TEM images of AgNPs attached to PS NSs after synthesis.
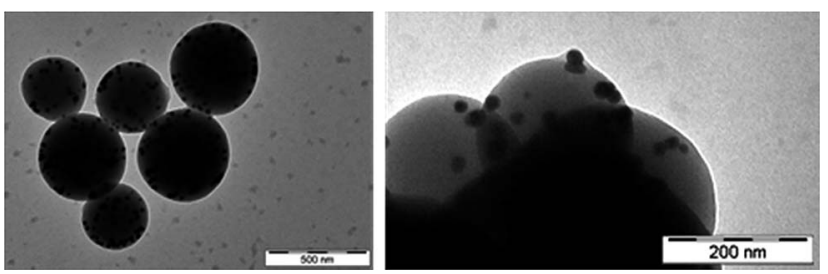

Fig. 4 TEM images of AgNPs encapsulated in the PS NSs after sonication demonstrating the full encapsulation of nanoparticles.

Open containers could be observed in only a few samples. SEM analysis clearly showed that the AgNPs were also present inside the container cavity (Fig. 6F), suggesting that the AgNPs are indeed well integrated within the ceria shell. The mechanism by which the AgNPs move from the container cavity to the outside of the ceria shell is still not fully understood. However, it can be hypothesized that by the diffusion process during the coating with $\mathrm{CeO}_{2}$, or indeed the transport process, which involves the extraction of the polystyrene core out of the containers, be it either by heating or dissolution, may also entrain partial transport of the AgNPs to the outer side of the containers.

The silver release from these hybrid $\mathrm{AgNP} / \mathrm{CeO}_{2}$ containers was determined by ICP-OES. In contrast to $\mathrm{AgNO}_{3} / \mathrm{CeO}_{2}$ nanocontainers (Fig. 2), the silver release from $\mathrm{AgNP} / \mathrm{CeO}_{2}$ containers prepared by calcination was much slower (Fig. 7). The AgNP/CeO $\mathrm{C}_{2}$ containers obtained by calcination therefore enabled a silver release over a period of at least 3 months. Even after this extended period of time, silver release was still found to be considerable. It is well known that silver ions, even at low concentrations, have an enhanced antimicrobial activity, ${ }^{30}$ which suggests that this newly designed silver-containing material could potentially prevent bacterial invasion during the most important period following implant surgery.

On the other hand, $\mathrm{AgNP} / \mathrm{CeO}_{2}$ containers prepared by dissolution have a lower and faster silver release, i.e. over a period of less than a month (Fig. 8). This is explained by the dissolution steps in which a considerable amount of silver was washed away. The containers prepared by dissolution would

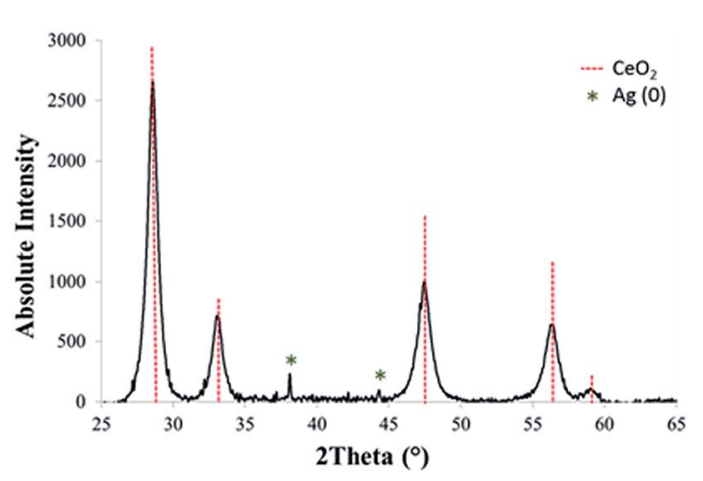

Fig. $5 \mathrm{XR}$ diffractogram of $\mathrm{AgNP} / \mathrm{CeO}_{2}$ containers. Red lines and green stars correspond to the peak positions of ceria and silver XRD patterns respectively. 


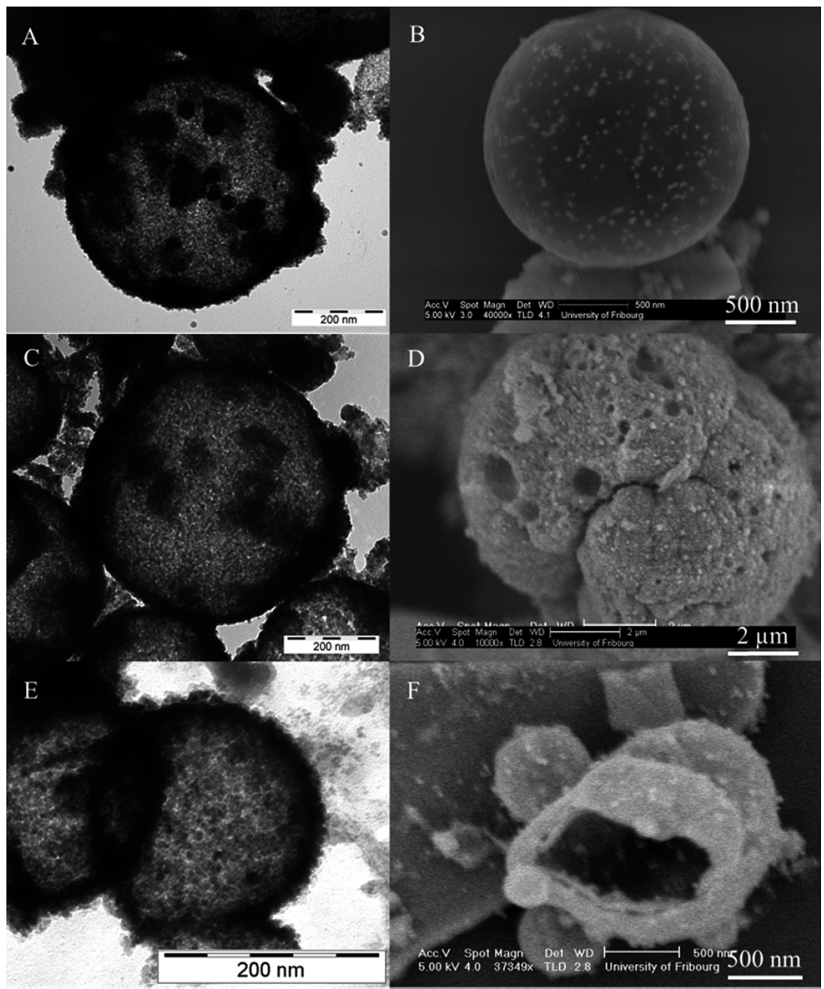

Fig. 6 TEM images ( $A, C$ and $E$ ) and SEM images ( $B, D$ and $F$ ) of silver nanoparticles encapsulated in the PS NSs and coated with $\mathrm{CeO}_{2}$ before the removal of the polystyrene core (A and B), and after the removal of the core via calcination ( $C$ and $D$ ) and via dissolution in xylene ( $E$ and $F$ ). Silver nanoparticles can be observed in all images. In SEM images, they clearly appear on the surface of the $\mathrm{CeO}_{2}$ coating, as well as in the cavity of the broken containers (F).

therefore be less efficient in the prevention of infections compared to the ones prepared by calcination.

To the best of our knowledge, this is the first time that AgNPs are encapsulated into inorganic containers using a method in which AgNPs are first encapsulated into a PS template. This resulted in well-dispersed AgNPs throughout the $\mathrm{CeO}_{2}$ shell and a silver release exceeding 3 months. In addition, despite the fact that orthopaedic implants are normally in place for ten to

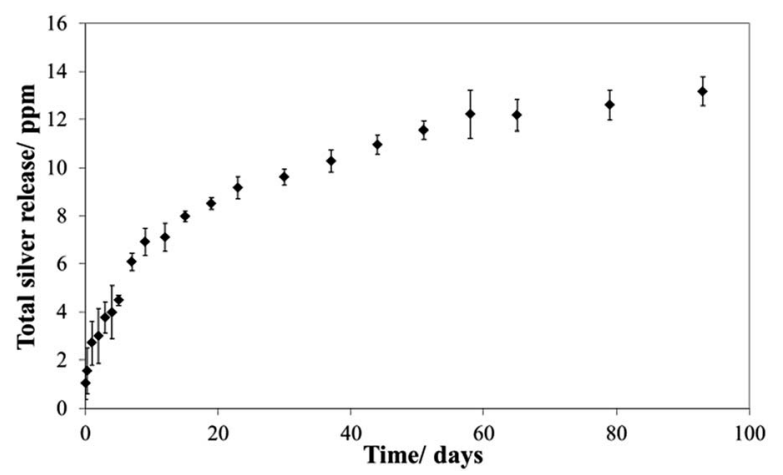

Fig. 7 Silver release as a function of immersion time for $\mathrm{AgNP} / \mathrm{CeO}_{2}$ containers prepared by calcination.

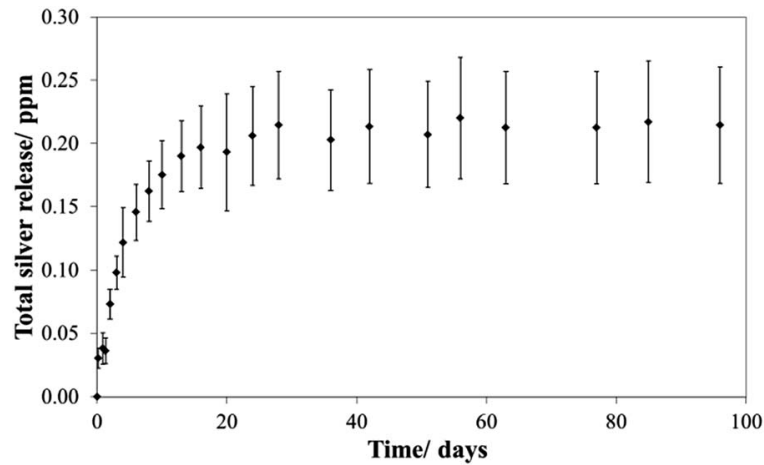

Fig. 8 Silver release as a function of immersion time for $\mathrm{AgNP} / \mathrm{CeO}_{2}$ containers prepared by dissolution. Data are the $\%$ mean \pm standard error of the mean $(n=4)$.

fifteen years, ${ }^{31}$ only a few studies described the long-term release of silver from implant materials. ${ }^{32}$ The $\mathrm{AgNP} / \mathrm{CeO}_{2}$ containers obtained by calcination are therefore very promising for the development of long-term antibacterial implant coatings.

\subsection{Antibacterial tests}

Neither tests for the zone of growth inhibition or MBC determination showed any inhibition of $E$. coli growth for empty $\mathrm{CeO}_{2}$ nanocontainers (Fig. 9A). On the other hand, both silvercontaining $\mathrm{CeO}_{2}$ containers demonstrated heightened antimicrobial activity (Fig. 9B and C), indicating the intrinsic antimicrobial properties of silver. The zone of inhibition of $\mathrm{AgNO}_{3} /$ $\mathrm{CeO}_{2}$ nanocontainers was $4 \mathrm{~mm}$ in radius, while the inhibition zone of $\mathrm{AgNP} / \mathrm{CeO}_{2}$ containers was $2 \mathrm{~mm}$ in radius. $\mathrm{AgNP} / \mathrm{CeO}_{2}$ containers showed a slower release of silver, explaining why the $\mathrm{AgNO}_{3} / \mathrm{CeO}_{2}$ nanocontainers elicited a larger inhibitory zone in such a short time period (i.e. overnight incubation). $\mathrm{AgNP} / \mathrm{CeO}_{2}$ containers prepared by dissolution also showed an inhibitory zone as for $\mathrm{AgNP} / \mathrm{CeO}_{2}$ containers prepared by calcination.

The MBC determination by the broth dilution method demonstrated that $\mathrm{AgNO}_{3} / \mathrm{CeO}_{2}$ nanocontainers have a $\mathrm{MBC}$ of $93 \pm 5 \mathrm{mg} \mathrm{mL}^{-1}\left(0.54 \pm 0.03 \mathrm{~mol} \mathrm{~L}^{-1}\right)$ and for $\mathrm{AgNP} / \mathrm{CeO}_{2}$ containers, the MBC is $117 \pm 6 \mathrm{mg} \mathrm{mL}^{-1}\left(0.68 \pm 0.03 \mathrm{~mol} \mathrm{~L}^{-1}\right)$. These findings further demonstrate the heightened antibacterial activity of silver-containing $\mathrm{CeO}_{2}$ containers. The enhanced antibacterial activity of $\mathrm{AgNO}_{3} / \mathrm{CeO}_{2}$ nanocontainers is consistent with their higher silver load being released after a one-day
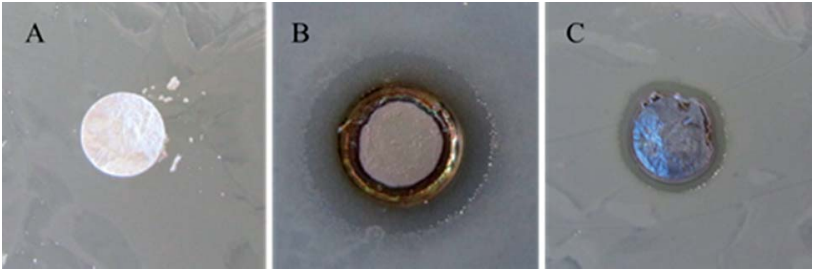

Fig. 9 Photographs of disc diffusion tests $(n=3)$ of $\mathrm{CeO}_{2}$ nanocontainers (A), $\mathrm{AgNO}_{3} / \mathrm{CeO}_{2}$ nanocontainers (B) and $\mathrm{AgNP} / \mathrm{CeO}_{2}$ containers (C). 
period (Fig. 2) compared to the silver release of $\mathrm{AgNP} / \mathrm{CeO}_{2}$ containers (Fig. 7).

\subsection{Epithelial cell cytotoxicity and morphology}

Fig. 10 shows that $\mathrm{CeO}_{2}$ nanocontainers elicit no significant increase $(p>0.05)$ in $\mathrm{LDH}$ release from the A549 cells at either time point or concentration tested. However, further analysis via LSM highlighted that these nanocontainers induced signs of apoptosis (e.g. shrinkage of the cell size and membrane as well as condensed nuclear regions (Fig. 10B)). In addition, the monolayer, as clearly shown in the sample treated with cell culture media only (negative control) (Fig. 10A), was completely disrupted by the $\mathrm{CeO}_{2}$ nanocontainers. Thus, the lack of any detectable LDH release can be attributed to the fact that the cell membrane remained intact. Although $\mathrm{CeO}_{2}$ NPs have been shown to elicit a heightened antioxidant effect, ${ }^{33}$ the potential for this nanomaterial to cause apoptosis in A549 cells is also well known, as recently reported by Mittal and Pandey. ${ }^{34}$ While Mittal and Pandey ${ }^{34}$ highlighted the mechanistic pathways associated with the onset of cell death following interactions (i.e. uptake) of $\mathrm{CeO}_{2}$ NPs with A549 cells, in the present study the apoptosis observed can be strongly attributed to the rough surface of the $\mathrm{CeO}_{2}$ nanocontainers that the cells were cultured upon. Although an imperative understanding of the raw form of the $\mathrm{CeO}_{2}$ nanocontainers has been gained here, it is hypothesized that the effect of $\mathrm{CeO}_{2}$ nanocontainers on cell morphology will be significantly reduced following the impregnation of the $\mathrm{CeO}_{2}$ nanocontainers into a polymer-based biomaterial for their eventual application.

Following exposure to $\mathrm{AgNO}_{3} / \mathrm{CeO}_{2}$ and $\mathrm{AgNP} / \mathrm{CeO}_{2}$ containers respectively, the epithelial cell monolayer was also significantly disrupted, as evident in Fig. 10C and D. With respect to the $\mathrm{AgNO}_{3} / \mathrm{CeO}_{2}$ nanocontainer exposure, a significantly lower $(p<0.05) \mathrm{LDH}$ release compared to control levels was observed for both time points and concentrations tested. This effect, augmented further by the noticeable unspecific rhodamine-phalloidin staining throughout the sample, can be associated with the nanocontainers inducing immediate necrosis following exposure to the A549 cells. This explains the low $\mathrm{LDH}$ concentration in the culture medium for $\mathrm{AgNO}_{3} / \mathrm{CeO}_{2}$. Since cell death occurred rapidly after exposure, cells could not build up a LDH load over the incubation periods, as was the case for the other samples and the control. This effect is most likely due to a rapid silver ion release from these nanocontainers that causes membrane disruption and actin depolymerisation, as previously reported by Cheng and colleagues. ${ }^{35}$

With regard to the $\mathrm{AgNP} / \mathrm{CeO}_{2}$ nanocontainers, similar to the $\mathrm{CeO}_{2}$ nanocontainers, a limited, non-significant $(p>0.05)$ cytotoxicity was observed after a 4 day exposure. Following a 7 day exposure, however, the $\mathrm{AgNP} / \mathrm{CeO}_{2}$ nanocontainers elicited a significant increase $(p<0.05)$ in LDH activity at both concentrations tested. This effect can be attributed to a higher concentration of silver in the medium after 7 days' exposure that constantly interacts with the cells during this prolonged period. Subsequent LSM analysis supported the LDH analysis and further indicated that $\mathrm{AgNP} / \mathrm{CeO}_{2}$ containers could also
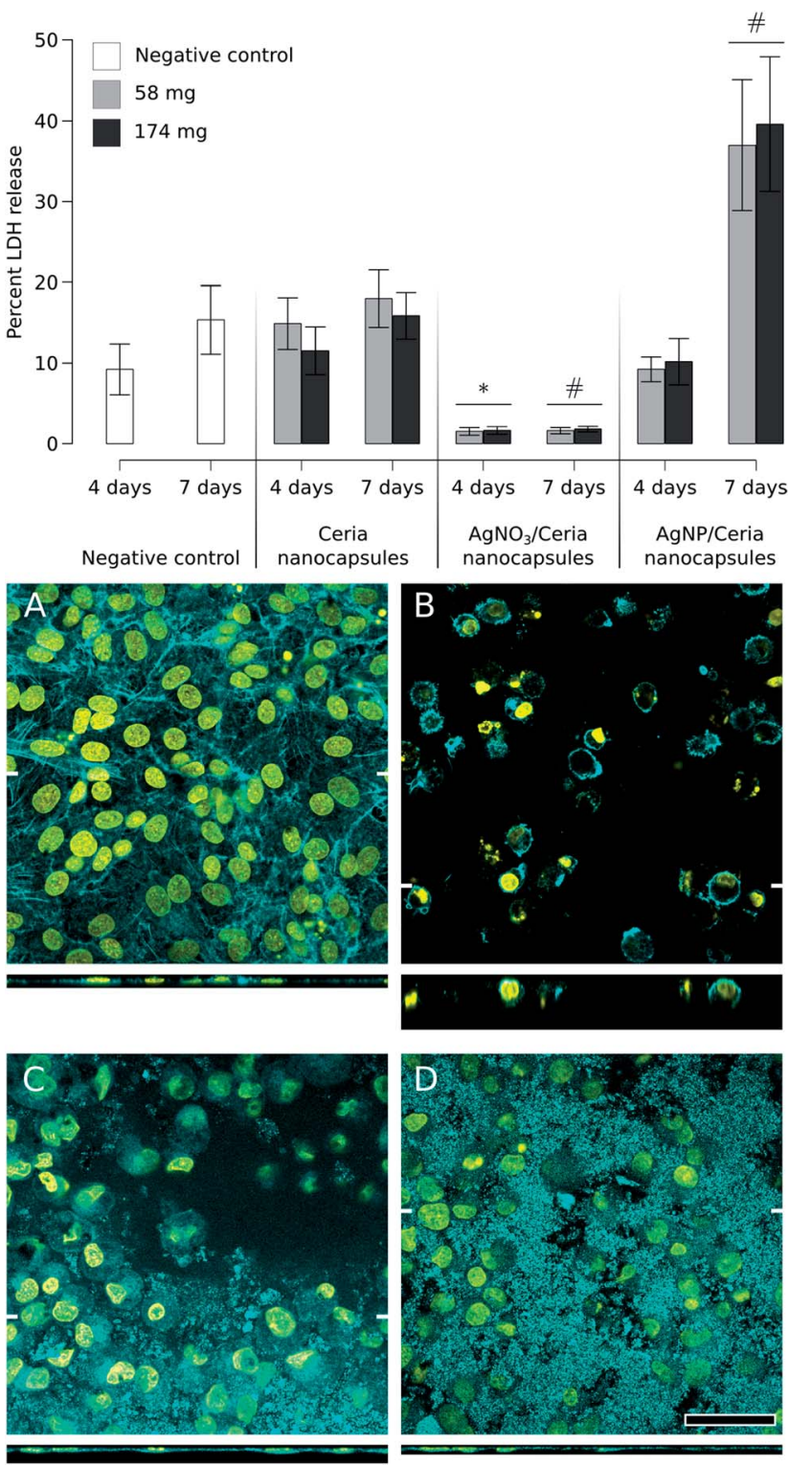

Fig. 10 Cytotoxicity (bar graph) of $58 \mathrm{mg}$ per well (light grey) and 174 mg per well (black) of $\mathrm{CeO}_{2}$ nanocontainers, $\mathrm{AgNO}_{3} / \mathrm{CeO}_{2}$ nanocontainers and $\mathrm{AgNP} / \mathrm{CeO}_{2}$ containers after 4 and 7 days of exposure to A549 epithelial cells. Cell culture media only served as the negative control in both occasions (white bars). Data are the $\%$ mean \pm standard error of the mean compared to the positive control (0.2\% TritonX 100$)$ $(n=3)$. *Represents $p<0.05$ compared to the negative control at 4 days. \#Represents $p<0.05$ compared to the negative control at 7 days. LSM images showing the $X Y$ panel and the $X Z$ panel (below $X Y$ image) of the negative control (cell culture media only) (A), $\mathrm{CeO}_{2}$ nanocontainers (B), $\mathrm{AgNO}_{3} / \mathrm{CeO}_{2}$ nanocontainers (C) and $\mathrm{AgNP} / \mathrm{CeO}_{2}$ containers (D). The scale bar corresponds to $50 \mu \mathrm{m}$. The nuclei are stained with DAPI (yellow) and the F-actin with rhodamine-phalloidin (cyan).

induce necrosis in the A549 cells, showing effects similar to the $\mathrm{AgNO}_{3} / \mathrm{CeO}_{2}$ sample, although in a slower fashion (Fig. 10D). It is important to note, however, that the $\mathrm{AgNP} / \mathrm{CeO}_{2}$ containers elucidated a slower cytotoxicity than the $\mathrm{AgNO}_{3} / \mathrm{CeO}_{2}$ containers due to a gradual, instead of immediate, silver release from the nanocontainers. 
More detailed descriptions of AgNP effects on cells can be found elsewhere. ${ }^{32}$ As an example, Mukherjee et $a .^{36}$ have demonstrated that biosynthesized AgNPs are more toxic towards cancerous cells, such as A549 cells, due to the cancerous cells' tendency to acidify their environment. The development of silver-containing materials can therefore find use in biomedical applications as an antibacterial or anticancer agent.

\section{Conclusions}

In conclusion, it was demonstrated that it is possible to use $\mathrm{CeO}_{2}$ nanocontainers to efficiently encapsulate either $\mathrm{AgNO}_{3}$ or AgNPs. These materials demonstrated an enhanced antimicrobial activity against $E$. coli, whereas in human cells (A549 epithelial cells) all three samples, when tested in their raw form, were observed to induce a form of cell death (i.e. apoptosis $\left(\mathrm{CeO}_{2}\right.$ nanocontainers and $\mathrm{AgNP} / \mathrm{CeO}_{2}$ nanocontainers) or necrosis $\left(\mathrm{AgNO}_{3} / \mathrm{CeO}_{2}\right.$ and $\mathrm{AgNP} / \mathrm{CeO}_{2}$ nanocontainers)). The $\mathrm{AgNP} / \mathrm{CeO}_{2}$ nanocontainers are particularly interesting for the prevention of implant-related infections thanks to their longterm silver release.

These effects, however, which can be attributed to the rough surface of the $\mathrm{CeO}_{2}$ nanocontainers and the kinetics of silver release, could be controlled by encapsulating the materials into a biomaterial (i.e. a polymer). From these findings, it can be suggested that with further emphasis towards increasing their biocompatibility, these newly designed $\mathrm{AgNP} / \mathrm{CeO}_{2}$ nanocontainers may offer an advantageous strategy towards potentially preventing bacterial infections following implant surgery.

\section{Acknowledgements}

We are grateful to the Swiss National Science Foundation, the University of Fribourg, the Adolphe Merkle Foundation, FriMat and the NCCR "Bioinspired Materials" for generously supporting this project. We also thank Dr N. H. Kwon and Dr P. S. Brunetto for the SEM images and Y. Umehara for her help with the eukaryotic cell culture.

\section{Notes and references}

1 E. M. Hetrick and M. H. Schoenfisch, Chem. Soc. Rev., 2006, 35, 780.

2 R. O. Darouiche, N. Engl. J. Med., 2004, 350, 1422-1429.

3 R. M. Donlan and J. W. Costerton, Clin. Microbiol. Rev., 2002, 15, 167-193.

4 A. G. Gristina, Science, 1987, 237, 1588-1595.

5 (a) K. A. Poelstra, N. A. Barekzi, A. M. Rediske, A. G. Felts, J. B. Slunt and D. W. Grainger, J. Biomed. Mater. Res., 2002, 60, 206-215; (b) M. Emmerson, New Horizons: Science \& Practice of Acute Medicine, 1998, 6, S3-S10.

6 P. Gilbert, P. J. Collier and M. R. W. Brown, Antimicrob. Agents Chemother., 1990, 34, 1865-1868.

7 S. Hackenberg, A. Scherzed, M. Kessler, S. Hummel, A. Technau, K. Froelich, C. Ginzkey, C. Koehler, R. Hagen and N. Kleinsasser, Toxicol. Lett., 2011, 201, 27-33.
8 (a) T. V. Slenters, I. Hauser-Gerspach, A. U. Daniels and K. M. Fromm, J. Mater. Chem., 2008, 18, 5359-5362. http:// pubs.rsc.org/en/content/articlepdf/2008/jm/b813026d; (b) O. Gordon, T. Vig Slenters, P. S. Brunetto, A. E. Villaruz, D. E. Sturdevant, M. Otto, R. Landmann and K. M. Fromm, Antimicrob. Agents Chemother., 2010, 54, 4208-4218.

9 P. S. Brunetto and K. M. Fromm, Chimia, 2008, 62, 249-252. 10 (a) A. Montali, Injury, 2006, 37(suppl. 2), S81-S86; (b) M. J. Santillan, N. E. Quaranta and A. R. Boccaccini, Surf. Coat. Technol., 2010, 205, 2562-2571; (c) J. Wu, S. Hou, D. Ren and P. T. Mather, Biomacromolecules, 2009, 10, 2686-2693.

11 V. Alt, T. Bechert, P. Steinrucke, M. Wagener, P. Seidel, E. Dingeldein, E. Domann and R. Schnettler, Biomaterials, 2004, 25, 4383-4391.

12 A.-H. Pei, Z.-W. Shen and G.-S. Yang, Mater. Lett., 2007, 61, 2757-2760.

13 I. Kartsonakis, I. Daniilidis and G. Kordas, J. Sol-Gel Sci. Technol., 2008, 48, 24-31.

14 C. E. Ashley, E. C. Carnes, G. K. Phillips, D. Padilla, P. N. Durfee, P. A. Brown, T. N. Hanna, J. Liu, B. Phillips, M. B. Carter, N. J. Carroll, X. Jiang, D. R. Dunphy, C. L. Willman, D. N. Petsev, D. G. Evans, A. N. Parikh, B. Chackerian, W. Wharton, D. S. Peabody and C. J. Brinker, Nat. Mater., 2011, 10, 389-397.

15 (a) A. Madadlou, D. Iacopino, D. Sheehan, Z. Emam-Djomeh and M. E. Mousavi, Biochim. Biophys. Acta, 2010, 1800, 459465; (b) Y. Urabe, T. Shiomi, T. Itoh, A. Kawai, T. Tsunoda, F. Mizukami and K. Sakaguchi, ChemBioChem, 2007, 8, 668-674.

16 S. S. Hardas, D. A. Butterfield, R. Sultana, M. T. Tseng, M. Dan, R. L. Florence, J. M. Unrine, U. M. Graham, P. Wu, E. A. Grulke and R. A. Yokel, Toxicol. Sci., 2010, 116, 562-576.

17 F. R. Cassee, E. C. van Balen, C. Singh, D. Green, H. Muijser, J. Weinstein and K. Dreher, Crit. Rev. Toxicol., 2011, 41, 213229.

18 (a) A. S. Karakoti, N. A. Monteiro-Riviere, R. Aggarwal, J. P. Davis, R. J. Narayan, W. T. Self, J. McGinnis and S. Seal, JOM, 2008, 60, 33-37; (b) T. Xia, M. Kovochich, M. Liong, L. Mädler, B. Gilbert, H. Shi, J. I. Yeh, J. I. Zink and A. E. Nel, ACS Nano, 2008, 2, 2121-2134; (c) D. Schubert, R. Dargusch, J. Raitano and S.-W. Chan, Biochem. Biophys. Res. Commun., 2006, 342, 86-91.

19 I. A. Kartsonakis, P. Liatsi, I. Daniilidis and G. Kordas, J. Am. Ceram. Soc., 2008, 91, 372-378.

20 D. D. Evanoff and G. Chumanov, J. Phys. Chem. B, 2004, 108, 13948-13956.

21 A. S. Kumbhar and G. Chumanov, Chem. Mater., 2009, 21, 2835-2839.

22 B. Bonev, J. Hooper and J. Parisot, J. Antimicrob. Chemother., 2008, 61, 1295-1301.

23 K. E. Cooper, Nature, 1955, 176, 510-511.

24 I. Wiegand, K. Hilpert and R. E. W. Hancock, Nat. Protoc., 2008, 3, 163-175.

25 J. McFarland, JAMA, J. Am. Med. Assoc., 1907, 14, 1176-1178. 
26 B. M. Rothen-Rutishauser, S. G. Kiama and P. Gehr, Am. J. Respir. Cell Mol. Biol., 2005, 32, 281-289.

27 A. Lehmann, C. H. Brandenberger, F. Blank, P. Gehr and B. Rothen-Rutishauser, A 3D model of the human epithelial airway barrier, in Alternatives to Animal Testing, ed. M. L. Yarmush and R. S. Langer, Artech House, 2010, vol. 239-260.

28 (a) F. Chen, Y. Cao and D. Jia, Appl. Surf. Sci., 2011, 257, 9226-9231; (b) Y. S. Chaudhary, S. Panigrahi, S. Nayak, B. Satpati, S. Bhattacharjee and N. Kulkarni, J. Mater. Chem., 2010, 20, 2381; (c) K. Kalimuthu, R. S. Babu, D. Venkataraman, M. Bilal and S. Gurunathan, Colloids Surf., B, 2008, 65, 150-153.

29 (a) C. Damm, H. Münstedt and A. Rösch, J. Mater. Sci.: Mater. Med., 2007, 42, 6067-6073; (b) M. Z. Kassaee, A. Akhavan, N. Sheikh and A. Sodagar, J. Appl. Polym. Sci., 2008, 110, 1699-1703; (c) D. Zampino, T. Ferreri, C. Puglisi,
M. Mancuso, R. Zaccone, R. Scaffaro and D. Bennardo, J. Mater. Sci.: Mater. Med., 2011, 46, 6734-6743.

30 A. Panáček, L. Kvítek, R. Prucek, M. Kolář, R. Večeřová, N. Pizúrová, V. K. Sharma, T. Navěčná and R. Zbořil, J. Phys. Chem., 2006, 110, 16248-16253.

31 C. Yao, V. Perla, J. L. McKenzie, E. B. Slamovich and T. J. Webster, J. Biomed. Nanotechnol., 2005, 1, 68-73.

32 S. Eckhardt, P. S. Brunetto, J. Gagnon, M. Priebe, B. Giese and K. M. Fromm, Chem. Rev., 2013, 113, 4708-4754.

33 L. L. Wong and J. F. McGinnis, Adv. Exp. Med. Biol., 2014, 801, 821-828.

34 S. Mittal and A. K. Pandey, BioMed Res. Int., 2014, 2014, 891934.

35 X. Cheng, W. Zhang, Y. Ji, J. Meng, H. Guo, J. Liu, X. Wu and H. Xu, RSC Adv., 2013, 3, 2296-2305.

36 S. Mukherjee, D. Chowdhury, R. Kotcherlakota, S. Patra, B. Vinothkumar, M. P. Bhadra, B. Sreedhar and C. R. Patra, Theranostics, 2014, 4, 316-335. 